\title{
Research on the Similarities and Differences between Flash ActionScript based Animation Design Technique and Traditional Design Pattern
}

\author{
Xiaoxia Yang ${ }^{1}$ \\ Weifang University of Science \& Technology \\ Shouguang 262700 China
}

\begin{abstract}
With the rapid development of animation design and other computer science techniques, the application of computer based design pattern is urgently appreciated. In this paper, we conduct research on the similarities and differences between Flash ActionScript based animation design technique and traditional design pattern. Current computer animation technology has developed rapidly at home and abroad, in the production of $2 \mathrm{D}$ and $3 \mathrm{D}$ animation, creating many new methods, new technology, using the computer aided animation in different degree to replace the manual animation technology, computerized gradually. We could significantly conclude from the user interface and the sample example of the pattern of computer based animation design. In the future, we plan to research more to touch the latest techniques related to flash technique.
\end{abstract}

Keywords: Flash ActionScript; Animation Design; Traditional Approach; Design Pattern.

\section{Introduction}

For many students who have an interest in combining their creative artistic side and the use of digital software technologies, the need to gain skills in programming and scripting is growing. Computer after intervention animation, caused a revolution in the field of animation, the revolution in two aspects, one is speed effect. Current computer animation technology has developed rapidly at home and abroad, in the production of 2D and 3D animation, creating many new methods, new technology, using the computer aided animation in different degree to replace the manual animation technology, computerized gradually. 2D animation and 3D animation combination which will be combined with two-dimensional animation of real live with the three dimensional animation and live-action combine with reality. Therefore, the combination of the optimal point should be the future direction of computer animation. Animation is beautiful, witty, humorous and wonderful. Whether domestic or foreign, not only love children, adults also enjoy watching, animated film with its unique artistic charm, attract audiences. Animation has long been in short supply, however, cannot satisfy the needs of the audience, the contradiction of demand and supply is more and more sharp, is always the same between China and developed countries, just different levels, of course, causes of this kind of situation has a lot of ways. Now, thanks to the development of animation technology background activities, sometimes statistical up dirty movie at least also want to draw more than the background. To tens of millions of original animation manuscript paper, all transferred to transparent bright on a chip, this process is called tracing color, is positive tracing to its request, after air on the back all sorts of color, and between color and color not mutual penetration, invasion, line is very clear. There next working procedure is responsible for inspection, the pursuit of painting, animation and background in Ming set on, check, at the same time to clean each finished product, do not have dust, fingerprints, and stroke. Finally, the layered background and animation in the camera on the shelf, with the movie camera, one by one, each lattice plane filming. Scripting languages have been supported in many animation, 3D modelling and virtual studio design software packages [1-2]. 
To deal with the mentioned challenges, in this paper, we conduct research on the similarities and differences between Flash ActionScript based animation design technique and traditional design pattern. Every progress, science will have a great influence on the change in the field of art and design, as a form of art which also became prosperous development momentum. In the 20th century, the impact on the art of science and technology is becoming more intense and rapidly and the related development of digital technology for art created more broad space for performance. In the early time of 1980s, computer graphic art design into modern cutting-edge visual representation methods and form [3-4]. The global digital content is also in constant extension to the deeper and wider areas, and the industry will become one of the most promising industries in China. In the following sections, we will introduce the issues in detail with comment.

\section{The Comparison Research between the Patterns}

The General Overview. The emergence of new forms of communication and media, the content of visual communication art design, is greatly enriched and expanded. New media art design theory and aesthetic category inherited part of the theoretical system of traditional visual communication design. The theoretical system of traditional visual communication design is still can be used as a digital media art design theory basis. The main advantage of new media animation compared to traditional animation can be spread from creator, audience and channel manifested in three aspects. From the perspective of the creator, including independent creators, creative digital and remote cooperative group, multi-channel advantage than traditional animation and profit etc. Viewing from the Angle of the audience, the private media, film, animation type diversity and richness is one of the main types of audiences. From the perspective of media communication, network communication, audience interaction and network natural elimination rate is an important means to guarantee the quality of animation and the content popularity. Thus, we can from these aspects to summarize and the main advantages of the new media animation. New media art design is the product of The Times, it has the advanced nature of The Times, its form is more rich, more information, more be scientific, times, so in the new media also need to innovate in the design of traditional design theory system which must according to the information communication in the form of compound, subject of comprehensive and technical characteristics such as digital to perfect this emerging discipline. In the gollowing figure 1, we illustrate the flowchart of animation design and implementation.

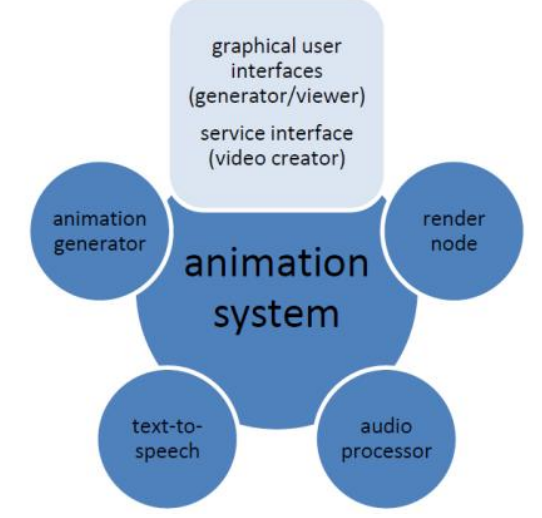

Fig. 1The General Flowchart of Animation Design and Implementation

New media art design is the combination of the rapid development of information technology and art, the form characteristics, aesthetic theory and knowledge of the structure of the study is the important link of the discipline development. Research to the further development of the optical principle, make the impressionists follow the principle of optics, the analysis of various relations and organizational object and at the same time, the application of optical research also contributed to the birth of photography and artistic creation has had a profound effect all these reflect the important role of art to science and technology. In the face of such a huge market environment and talent demand, domestic digital art and design is just beginning to rise which has not yet established the new media art theory system and talent cultivation system and led to 
the core of the design industry really need professional design talent shortage and new media art and design in many problems in the process of our development. In the case of the rapid development of the contemporary digital art design, the design of the digital media art theory and aesthetic theory is very weak.

The Traditional Pattern of Animation Design. With the continuous change of the new media technology, people's consumption and lifestyle is undergoing tremendous changes. Traditional reliance on cinema and television animation, for example, transmission and consumption mode is gradually replaced by a network. Use handmade animation in the early time it is all the animation picture on a piece of paper, even every one animation picture background to foil. By 60s, designers invented a transparent game in practice and the latter road we referred to as pieces instead of the paper the background as long as draw a moving body can divide three or four layers. On the background and environment of painting, each layer of material as can be all kinds of action can't more than four layers and the reform, have greatly enriched the expressive force of animation, it is a great progress in the history of the animation. It photograph the two links spends too much manpower and material resources, capital, time is too long. The traditional manual animation method is necessary. In Disney, Warner Bros, still use the traditional method. Application of mature manual cartoon animation techniques still has certain advantages. This process should be animated in a wide range of the main reasons for the lack of. In order to solve the new media art design discipline basic theory is weak, the industrial development bottleneck and other issues, on the basis of related research, industry and analyze the forefront of the latest research results, and connecting with the practice for a long time, it is concluded that the new media art design only solve discipline of inheritance and innovation and talent cultivation platform can be efficient and rapid development.

The Flash ActionScript based Animation Design. Computer animation is the combination of technology and art, caused a revolution in the field of animation, so to speak, the art show surprise effect. Now two aspects, one is the revolution outstanding surface greatly accelerated the second is the effect, the style of the breakthrough. The figure 2, we show the sample UI of ActionScript.

is not hard to see in the animation and

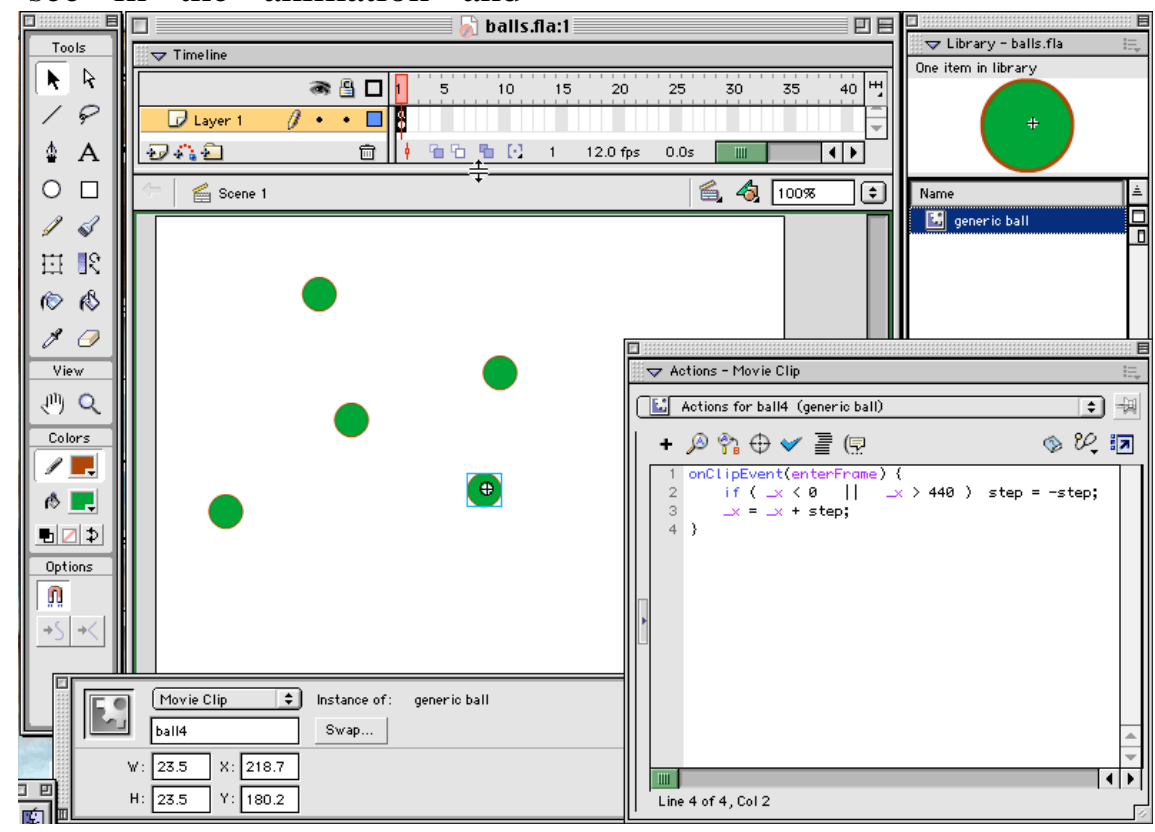

Fig. 2The General User Interface of the ActionScript 
Animation has a long history as a way to tell a story. Since its invention, people have used animation as a way to entertain, to convey an idea as well as to communicate a process. Computer animation, tracing line is not as long as hand draw a good painting input computer animation which will make the wire frame processing will automatically negligent hand lines are not in the joint thickness, different shades of the line, automatic closed will automatically united into the same specifications of the line according to the need but also will enter the black into a different color line which make local changes, and this in the manual tracing is very time-consuming. The next step was the development of interactive learning objects. According to the design principles of the general, we addressed the guideline learning by doing. The end product of Flash can be published though web and thus can be run on any platform. The most attractive feature of Flash is its strong graphic capability not available in other standard

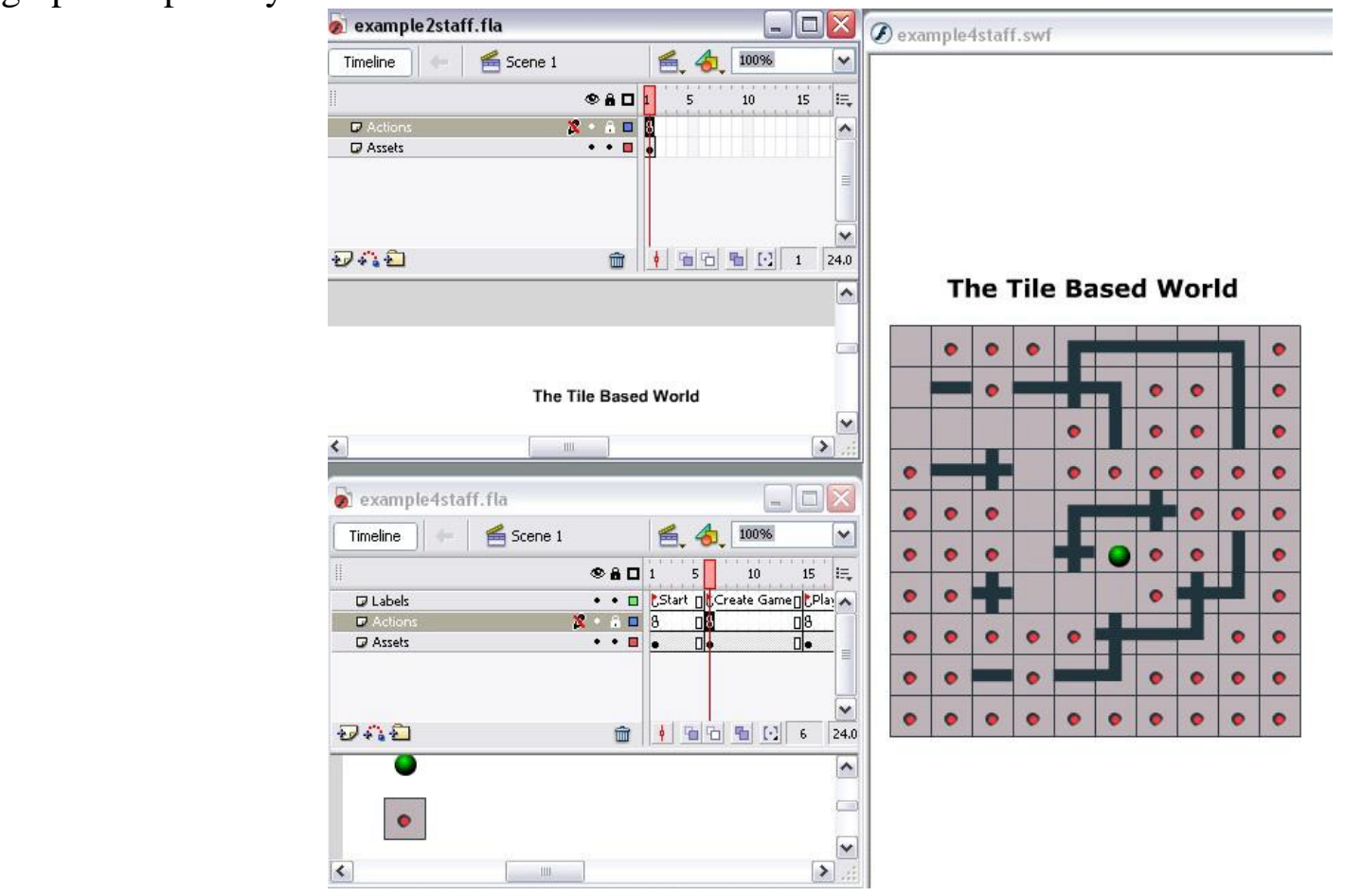

Fig. 3The General Sample of the Flash ActionScript based Animation Design programming languages. Computer animation can create a colorful world of 3D modelling, color, light and shade, texture, texture is very realistic which could produce different material texture or special surface effect such as gold, silver, copper, stainless steel, wood, marble, and transparent texture, effect is amazing. On the change of the acceleration, uniform speed and slowdown, can be calculated very accurately, a task for its fine degree is far from manual animation. This method is to use 3D software, establish a model of the object, the three dimensional modelling wireframes. In motion design, with a motion sensor which will demonstrate every movement posture by means of the image and the sensor is transmitted to the computer to realize the ideal gestures. Also can use the key frames or character skeleton animation modelling method to implement a series of actions. In the following figure, we show the sample result. 


\section{Conclusion}

In this paper, we conduct research on the similarities and differences between Flash ActionScript based animation design technique and traditional design pattern. Animation has long been in short supply, however, cannot satisfy the needs of the audience, the contradiction of demand and supply is more and more sharp, is always the same between China and developed countries, just different levels, of course, causes of this kind of situation has a lot of ways. Computer animation is the combination of technology and art, caused a revolution in the field of animation, so to speak, the art show surprise effect. We firmly believe that, the computer aided methodology of animation design will certainly obtain the trend of the design market. In the future, we plan to conduct more review on the related literatures and applications to capture better analyzing result.

\section{References}

[1] Hong-jin, L., \& San-xing, L. (2014). Design and development of children's coloring game based on actionscript3.0. Computer Knowledge \& Technology.

[2] Xue-zhi, L. (2014). The reform of competence-based website animation design curriculum. Journal of Liaoning Higher Vocational.

[3] Yong-xin, S. (2014). Design and implementation of sine function mapping based on flash as3. Computer Programming Skills \& Maintenance.

[4] F. N. L., Yang, L. W., \& Chen, C. Y. (2014). Research on mechanical animation based on flash programming technology. Computer-Aided Design, Manufacturing, Modeling and Simulation IV. 